\title{
Research on "First-Class" Financial Management of Power Grid Enterprises Based on IPA: Taking XX Power Supply Bureau as an Example
}

\author{
Junda Yang ${ }^{1}$, Yun Xia ${ }^{1}$, Liu Yang ${ }^{1} \&$ Zhongtao Zhang ${ }^{1}$ \\ ${ }^{1}$ Finance Department of International Business School, Jinan University, China \\ Correspondence: Liu Yang, Finance Department of International Business School, Jinan University, Qianshan \\ Road 206\#, Zhuhai City, Guangdong Province, Post NO. 519070, China.
}

Received: October 4, 2018 Accepted: October 31, $2018 \quad$ Online Published: November 25, 2018

doi:10.5539/jms.v8n4p74 URL: https://doi.org/10.5539/jms.v8n4p74

\begin{abstract}
Using the data collected by the questionnaire survey, this paper uses IPA (importance performance analysis) to analyze the financial performance and operation status of some financial data of the XX power supply bureau, and finds the indicators that need to maintain the advantages and the indicators that need to be improved. It can provide reference for the construction of power supply bureaus and power companies to create first-class indicators.
\end{abstract}

Keywords: power grid enterprises, financial performance evaluation, IPA

\section{Introduction}

Modern society cannot develop without electricity. The steady and sustainable development of power enterprises is related to national energy security and the lifeblood of national economy. As a basic industry of a country, the operation status of the power industry is related to national economy and people's livelihood, to the government, enterprises, families and individuals, and to the normal operation of the whole society, playing a vital role in the national economic development. Since the reform and opening up, China's economic development has attracted worldwide attention, and the demand for power is increasing. The expansion of power sales has stimulated the development of the whole power industry. Implementing the strategic deployment of power grid companies and striving to build world-class enterprises is the main working direction of power grid enterprises at the present stage.

Enterprise financial management is a core problem in the development of enterprises, in order to achieve a world-class level of financial management, need scientific and accurate comprehensive budget management, complete the cost control of lean, good asset structure, financial condition is moderate, the financial information system and business system well versed in all aspects such as comprehensive requirements. IPA can simply and intuitively distinguish the advantages and disadvantages of each key indicator, and then optimize the allocation of resources, so as to promote more efficient improvement of enterprise operating strength and financial performance. Therefore, from the perspective of financial performance management, IPA related theory and grid enterprise characteristics, this paper uses relevant innovation models to achieve the following objectives:

(1) To provide operational ideas for grid companies to improve their operating efficiency and achieve a scientific and rational goal of achieving first-class financial performance. Although the research on enterprise performance evaluation at home and abroad has been mature, there are not many studies on how to select the best among the best and set up a model specifically for optimizing the financial performance of grid enterprises. This paper hopes to help grid companies quickly identify the current status of key financial indicators that affect the company's "first-class" goal by building a more targeted financial performance evaluation model. It also provides reference for other people's research in the later period.

(2) Through innovative analysis of financial performance indicators into the IPA model, it helps enterprises fully realize their advantages and disadvantages in the operation process, and allocate enterprise resources efficiently and reasonably to the operation and construction activities with more needed financial indicators.

(3) On the basis of the modeling analysis of the specific financial index data of the case company-XX power 
supply bureau, it can more reliably reflect the real situation of enterprise operation, find out the existing problems and propose solutions.

\section{Literature Review}

\subsection{Financial Performance Evaluation}

Financial performance evaluation of an enterprise mainly refers to the reasonable evaluation of the operating efficiency of an enterprise and the performance of operating personnel during a period of time through the application of operational research and mathematical statistics, the mastery of a specific indicator system, and the analysis through the combination of quantitative and qualitative analysis. There are many methods and evaluation systems for enterprise financial evaluation. Currently, there are three commonly used financial evaluation systems: traditional performance evaluation system, enterprise financial evaluation system based on balanced score card, and enterprise financial evaluation system based on added value of economy.

Traditional performance appraisal systems are commonly used. By studying the current operating conditions of enterprises, we can study and analyze the financial performance of enterprises from the perspective of financial indicators, and then find out the advantages and disadvantages of enterprise operation. How to select financial indicators to comprehensively and extensively measure the financial performance of an enterprise? Li (2005) used cluster analysis to measure the financial performance of an enterprise from five aspects: debt paying ability indicators, operation efficiency analysis indicators, profitability analysis indicators, stock investor profitability analysis indicators and enterprise development ability analysis indicators. Liu (2017) constructed the financial performance evaluation system of listed coal companies by adopting factor analysis method, which has 12 indicators from four aspects of profitability, operation capacity, debt paying capacity and growth capacity. Xu (2017) and $\mathrm{Xu}$ et al. (2014) adopted the gray correlation analysis method and BP neural network model to give the evaluation method of enterprise financial performance. It can be seen that the traditional performance evaluation system uses various mathematical model methods to quantify the financial indicators, and then evaluates the business status of enterprises.

\subsection{Importance Performance Analysis}

IPA model, which originated in the business field in 1970, was first published by Martilla and James (1977) in the marketing journal as a model, and has since been widely used in various fields such as health management, marketing, education and tourism. IPA mainly adopts the form of questionnaire survey to obtain relevant data. The evaluation method is simple and can show advantages and disadvantages intuitively and concisely. It is widely used in all walks of life. Peng (2006) used IPA model to analyze the areas where theme hotels should make efforts to improve and maintain advantages, and provided corresponding countermeasures for theme hotel operators to prepare to grasp the market and pay attention to customer experience. Zeng and Bao (2018) used IPA model to diagnose and analyze the core curriculum offered by the graduates from the two measuring dimensions of importance and satisfaction of the curriculum. They found out the problems existing in the curriculum offered, the formulation and implementation of the curriculum standards. And based on the results of IPA model, they put forward suggestions for improving the professional curriculum. In analyzing the competitiveness of attractions (Tian et al., 2009) and the degree of visitor satisfaction (Chen, 2013), IPA model were also be used.

The main point of IPA is to combine the importance measurement and performance analysis in a two-dimensional grid diagram as abscissa and ordinate respectively, and divide them into four quadrants according to the average importance and average performance of all indicators.

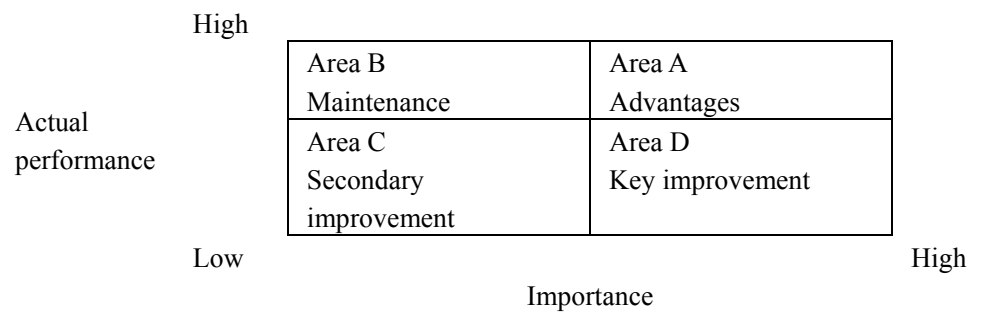

Figure 1. IPA analysis matrix diagram 
IPA method is divided into four quadrants, area $\mathrm{A}$ is the advantage area, and the importance of indicators and actual performance are higher, so the indicators in this area can be considered as dominant indicators. Area B is the maintenance area, the importance of indicators is relatively low, but the actual performance is higher, the indicators left in the region needed continue to maintain. Area $\mathrm{C}$ is the secondary improvement area, the importance of indicators and actual performance are relatively low, and the indicators in this area are secondary improvement indicators. Area D is the key improvement area, the importance of indicators is quite high, but the actual performance is not good, the indicators in this region need to be targeted improvement.

From above, this paper adopts IPA method to analyze the financial performance and operation status of XX power supply bureau with part of financial data as indicators, providing reference and reference for the construction of " first-class" indicator projects of power supply bureau and power enterprises.

\section{Study Design of IPA Model}

\subsection{Determination of Measurement Indicators}

According to the strategic deployment of the provincial network company, combined with the financial operation status of the XX power supply bureau, this paper starts from the four dimensions of income, cost, assets and debt and find the key business matter indicators that will drive these four dimensions to improve in each business area of the XX power supply bureau. The indicators selected are as follows.

Table 1. XX power supply bureau's financial performance "first-class" target impact indicator system

\begin{tabular}{|c|c|c|}
\hline Target layer (A) & Elements layer (B) & Indicators layer $(\mathrm{C})$ \\
\hline \multirow{36}{*}{$\begin{array}{l}\text { XX power supply } \\
\text { bureau's financial } \\
\text { performance } \\
\text { "first-class" target } \\
\text { impact indicator } \\
\text { system (A) }\end{array}$} & \multirow[t]{14}{*}{ Cost control (B1) } & $\begin{array}{l}\text { Cost of power supply (C1) Staff salary (C2) Depreciation and } \\
\text { amortization (C3) }\end{array}$ \\
\hline & & Controllable costs (C4) \\
\hline & & Production and operation cost (C5) \\
\hline & & Customer service cost (C6) \\
\hline & & Auxiliary cost of production (C7) \\
\hline & & Power purchase cost (C8) \\
\hline & & Line loss management (C9) \\
\hline & & Purchase price (C10) \\
\hline & & Quantity of electricity purchase (C11) \\
\hline & & Quantity of hydroelectric power (C12) \\
\hline & & Quantity of renewable energy power (C13) \\
\hline & & Quantity of province electricity (C14) \\
\hline & & Other costs (C15) Income tax burden (C16) \\
\hline & & $\begin{array}{l}\text { Giving guarantee (C17) Financial expense (C18) Interest expense } \\
\text { (C19) }\end{array}$ \\
\hline & \multirow[t]{5}{*}{ Income increase (B2) } & Regulated business income (C20) \\
\hline & & Power price $(\mathrm{C} 21)$ \\
\hline & & Average unit price of electricity sold within the province (C22) \\
\hline & & Quantity of electricity sale (C23) \\
\hline & & Quantity of electricity sale within the province (C24) \\
\hline & \multirow[t]{2}{*}{ Liabilities to optimize (B3) } & Debt structure (C25) Short-term loans (C26) \\
\hline & & Medium and long-term loans (C27) \\
\hline & \multirow[t]{15}{*}{ Assets strengthen (B4) } & Current assets (C28) Monetary fund (C29) \\
\hline & & Power charge receivable (C30) Inventories $(\mathrm{C} 31)$ \\
\hline & & Engineering materials (C32) \\
\hline & & Intangible assets (C33) Land (C34) \\
\hline & & Investment of informatization (C35) \\
\hline & & Fixed assets (C36) \\
\hline & & Assets received (C37) \\
\hline & & Community customer assets (C38) \\
\hline & & Power grid investment (C39) \\
\hline & & Marketing technology reform (C40) \\
\hline & & Production technology reform $(\mathrm{C} 41)$ \\
\hline & & Small infrastructure (C42) \\
\hline & & Main grid project (C43) \\
\hline & & Distribution grid project (C44) \\
\hline & & Asset retirement (C45) \\
\hline
\end{tabular}


We completely map the nine benchmarking first-class indicators of lean management in the financial field into the corresponding performance evaluation of key financial indicators to ensure the evaluation of indicators, and on this basis to complete the performance evaluation.

\subsection{Establishment of IPA Model}

The research object of this paper is the financial performance of an enterprise. Therefore, the indicator elements of this paper come from the financial indicators selected above. The perceived importance of the indicator elements comes from the questionnaire results of the employees in the enterprise. The performance of each indicator element is not the subjective perceived performance in the traditional IPA study, but the actual performance completion degree achieved in the actual production and operation process. The measurement method of indicator importance degree and performance completion degree is as follows:

(1) The degree of importance of indicator elements= Mean value of importance of indicator elements $/$ The highest importance value of the scale setting

(2) There are correlations between many indicator elements, such as Quantity of electricity purchase (C11) can be decomposed into three low-level indicators: Quantity of hydroelectric power (C12), Quantity of renewable energy power (C13) and Quantity of province electricity (C14). For low-level indicator elements, the performance completion of their indicator elements $=$ Actual performance value of indicator elements $/$ The average value of the target value of the indicator elements set by the enterprise. For the higher-level indicator elements, assuming that the indicator has $\mathrm{n}$ lower-level indicators, we make the performance completion of the senior indicator elements $=$

$$
\sum_{i=1}^{n} \frac{\text { Importance of the lower level indicator element } \mathrm{i} \times \text { Performance completion of indicator element } \mathrm{i}}{\sum_{i=1}^{n} \text { Importance of the lower level indicator element } \mathrm{i}}
$$

\subsection{Questionnaire Design}

We use the "first-class" decomposition indicator of financial performance confirmed in the previous step as the evaluation target, and use the 6-point Likert scale to design the questionnaire, where 1 means "Not at all", 2 means "Not important", and 3 means "Not too much", 4 means "Important", 5 means " More important" and 6 means "Very important". When filling out the questionnaire, the internal employees of the company can rely on their own work experience to score the importance of the optimization of each indicator to the company's goal of achieving "first-class" financial management. The financial performance of each indicator is calculated by the internal financial management personnel to provide us with the target value. The questionnaire was conducted by the internal staff of the grid company, and the research time was in the second half of 2018.and actual value of the corresponding financial indicators for the year. In this study, 52 employees were surveyed, 52 questionnaires were retrieved, and invalid questionnaires (at least one unanswered or obviously inconsistent questionnaire) were screened out and 52 valid questionnaires were obtained. The effective questionnaire recovery rate for this survey is $100 \%$.

\section{Application of IPA Analysis Model for Financial Indicators of Power Grid Enterprises}

\subsection{Questionnaire Reliability Analysis}

Reliability analysis is mainly used to evaluate the stability or reliability of the questionnaire. The current method of reliability measurement commonly used in academia is the Cronbach's alpha coefficient method founded in 1951 by Cronbah. This paper uses SPSS21.0 software to make a reliability analysis of the data results of the overall item based on the results of the questionnaire survey. The reliability measure shows a reliability Cronbach's $\alpha$ coefficient of 0.697 , which is higher than the minimum acceptable limit of 0.6 . It shows that the evaluation indicators used in this study are of good reliability and can be used for further data analysis and application.

Table 2. Reliability statistics

\begin{tabular}{ll}
\hline Cronbach's Alpha & Items \\
\hline .697 & 49 \\
\hline
\end{tabular}




\subsection{XX Power Supply Bureau Financial Indicator Elements IPA Model Results}

According to the results of the survey, the values calculated for all financial indicator elements are shown in the following table:

Table 3. The importance of the overall financial indicators and the degree of performance completion

\begin{tabular}{|c|c|c|c|c|c|}
\hline Indicator & $\begin{array}{l}\text { Mean of } \\
\text { importance }\end{array}$ & $\begin{array}{l}\text { Degree of } \\
\text { performance } \\
\text { completion }\end{array}$ & Indicator & $\begin{array}{l}\text { Mean of } \\
\text { importance }\end{array}$ & $\begin{array}{l}\text { Degree of performance } \\
\text { completion }\end{array}$ \\
\hline $\begin{array}{l}\text { B1 } \\
\text { Cost control }\end{array}$ & 0.9808 & 0.9756 & $\begin{array}{l}\text { C22 Average unit price of electricity sold } \\
\text { within the province }\end{array}$ & 1.0000 & 1.0071 \\
\hline $\begin{array}{l}\text { B2 } \\
\text { Income increase }\end{array}$ & 0.9872 & 1.0029 & C23 Quantity of electricity sale & 1.0000 & 0.9988 \\
\hline $\begin{array}{l}\text { B3 Liabilities to } \\
\text { optimize }\end{array}$ & 0.8389 & 1.0000 & $\begin{array}{l}\text { C24 Quantity of electricity sale within the } \\
\text { province }\end{array}$ & 1.0000 & 0.9988 \\
\hline B4 Assets strengthen & 1.0000 & 0.9225 & C25 Debt structure & 0.6346 & 1.0000 \\
\hline $\begin{array}{l}\text { C1 Cost of power } \\
\text { supply }\end{array}$ & 0.9808 & 1.0151 & C26 Short-term loans & 0.7051 & 1.0000 \\
\hline C2 Staff salary & 0.9135 & 1.0446 & C27 Medium and long-term loans & 0.7051 & 1.0000 \\
\hline $\begin{array}{l}\text { C3 Depreciation and } \\
\text { amortization }\end{array}$ & 0.8526 & 1.0159 & C28 Current assets & 0.7724 & 0.9890 \\
\hline $\begin{array}{l}\text { C4 } \\
\text { Controllable costs }\end{array}$ & 0.9712 & 0.9866 & C29 Monetary fund & 0.9968 & 0.9938 \\
\hline $\begin{array}{l}\text { C5 Production and } \\
\text { operation cost }\end{array}$ & 0.9103 & 0.9976 & C30 Power charge receivable & 0.9679 & 0.9542 \\
\hline $\begin{array}{l}\text { C6 Customer service } \\
\text { cost }\end{array}$ & 0.7821 & 0.9659 & C31 Inventories & 0.8814 & 1.0904 \\
\hline $\begin{array}{l}\text { C7 Auxiliary cost of } \\
\text { production }\end{array}$ & 0.7724 & 0.9946 & C32 Engineering materials & 0.7340 & 0.9065 \\
\hline $\begin{array}{l}\text { C8 Power purchase } \\
\text { cost }\end{array}$ & 0.9519 & 0.9482 & C33 Intangible assets & 0.8846 & 0.8959 \\
\hline $\begin{array}{l}\text { C9 Line loss } \\
\text { management }\end{array}$ & 0.9904 & 0.8532 & C34 Land & 0.9455 & 1.0000 \\
\hline C10 Purchase price & 0.8974 & 0.9991 & C35 Investment of informatization & 0.8878 & 0.7850 \\
\hline $\begin{array}{l}\text { C11 Quantity of } \\
\text { electricity purchase }\end{array}$ & 0.9359 & 1.0000 & C36 Fixed assets & 0.9904 & 0.8944 \\
\hline $\begin{array}{l}\text { C12 Quantity of } \\
\text { hydroelectric power }\end{array}$ & 0.6186 & 1.0000 & C37 Assets received & 0.8237 & 0.8514 \\
\hline $\begin{array}{l}\text { C13 Quantity of } \\
\text { renewable energy } \\
\text { power }\end{array}$ & 0.5673 & 1.0000 & C38 Community customer assets & 0.8686 & 0.8514 \\
\hline $\begin{array}{l}\text { C14 Quantity of } \\
\text { province electricity }\end{array}$ & 1.0000 & 1.0000 & C39 Power grid investment & 1.0000 & 0.9208 \\
\hline C15 Other costs & 0.6763 & 0.9569 & C40 Marketing technology reform & 0.9423 & 0.9359 \\
\hline $\begin{array}{l}\text { C16 Income tax } \\
\text { burden }\end{array}$ & 0.6282 & 0.8535 & C41 Production technology reform & 0.9423 & 0.9169 \\
\hline $\begin{array}{l}\text { C17 } \\
\text { Giving guarantee }\end{array}$ & 0.7628 & 1.0000 & C42 Small infrastructure & 0.9071 & 0.9250 \\
\hline $\begin{array}{l}\text { C18 } \\
\text { Financial expense }\end{array}$ & 0.7436 & 1.0000 & C43 Main grid project & 1.0000 & 0.8955 \\
\hline C19 Interest expense & 0.7564 & 1.0000 & C44 Distribution grid project & 1.0000 & 0.9318 \\
\hline $\begin{array}{l}\text { C20 Regulated } \\
\text { business income }\end{array}$ & 1.0000 & 1.0029 & C45 Asset retirement & 0.7949 & 0.9056 \\
\hline C21 Power price & 1.0000 & 1.0071 & & & \\
\hline
\end{tabular}

Through the importance level and performance completion of each indicator element in 2016, we can draw the IPA analysis matrix. For the importance of the indicator elements, we decided to calculate the value of 0.8756 by spss 21 based on the overall average of all indicator elements. For the performance completion degree, we take 1 as the baseline (the reference line is set as 1 , which is helpful to judge whether this indicator meets the 
performance target requirements of the enterprise, that is, whether it meets the actual value $=$ the target value). The IPA results of the financial data indicator layer of XX power supply bureau in 2016 are shown in the figure below.

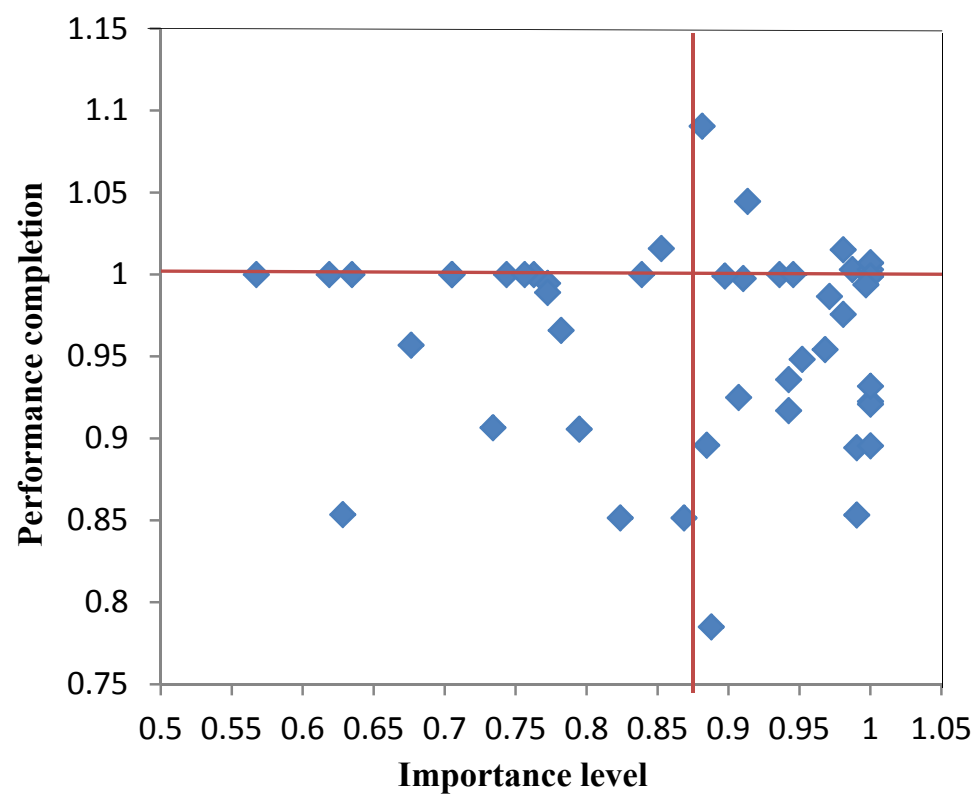

Figure 2. Figure IPA of financial indicators of XX power supply bureau in 2016

The indicators elements in the four partitions of IPA matrix are statistically analyzed, and the results are shown in the following table

Table 4. 2016 XX power supply bureau financial indicators IPA model partition

\begin{tabular}{ll}
\hline Year & 2016 \\
\hline Area A & B2 Income increase C1 Cost of power supply C2 Staff salary \\
& C11 Quantity of electricity purchase C14 Quantity of province electricity \\
& C20 Regulated business income C21 Power price \\
& C22 Average unit price of electricity sold within the province C31 Inventories \\
& C34 Land \\
Area B & B3 Liabilities to optimize C3 Depreciation and amortization \\
& C12 Quantity of hydroelectric power C13 Quantity of renewable energy power \\
& C25 Debt structure C26 Short-term loans C27 Medium and long-term loans \\
Area C & C6 Customer service cost C7 Auxiliary cost of production C15 Other costs \\
& C16 Income tax burden C17 Giving guarantee C18 Financial expense \\
& C19 Interest expense C28 Current assets C32 Engineering materials \\
Area D & C37 Assets received C38 Community customer assets C45 Asset retirement \\
& B1 Cost control B4 Assets strengthen C4 Controllable costs \\
& C5 Production and operation cost C8 Power purchase cost \\
& C9 Line loss management C10 Purchase price C23 Quantity of electricity sale \\
& C24 Quantity of electricity sale within the province C29 Monetary fund \\
& C30 Power charge receivable C33 Intangible assets \\
& C35 Investment of informatization C36 Fixed assets C39 Power grid investment \\
& C40 Marketing technology reform C41 Production technology reform \\
C42 Small infrastructure C43 Main grid project C44 Distribution grid project
\end{tabular}


Area A (Advantages): B2 Income increase C1 Cost of power supply C2 Staff salary

C11 Quantity of electricity purchase C14 Quantity of province electricity

C20 Regulated business income C21 Power price

C22 Average unit price of electricity sold within the province

C31 Inventories C34 Land

These indicators belong to high-importance and high-performance indicators, which are superior indicators of enterprise management and need to be maintained.

Area B (Maintenance): B3 Liabilities to optimize C3 Depreciation and amortization

C12 Quantity of hydroelectric power

C13 Quantity of renewable energy power

C25 Debt structure C26 Short-term loans

C27 Medium and long-term loans

The actual value of these indicators is equal to the target value set by the enterprise. At present, they have reached the performance requirements, but their importance is relatively low. Therefore, these are indicators that enterprises need to continue to consolidate.

Area C (Secondary improvement): C6 Customer service cost C7 Auxiliary cost of production C15 Other costs C16 Income tax burden

C17 Giving guarantee C18 Financial expense

C19 Interest expense C28 Current assets

C32 Engineering materials C37 Assets received

C38 Community customer assets C45 Asset retirement

The performance completion value of these indicators is less than 1, indicating that these indicators have not yet reached the performance requirements of enterprises, but the importance of these indicators is not high. Therefore, these are indicators that enterprises should gradually improve.

Area D (Key improvement): B1 Cost control B4 Assets strengthen C4 Controllable costs

C5 Production and operation cost C8 Power purchase cost

C9 Line loss management C10 Purchase price

C23 Quantity of electricity sale

C24 Quantity of electricity sale within the province

C29 Monetary fund C30 Power charge receivable

C33 Intangible assets C35 Investment of informatization

C36 Fixed assets C39 Power grid investment

C40 Marketing technology reform

C41 Production technology reform C42 Small infrastructure

C43 Main grid project C44 Distribution grid project

The performance completion of these indicators is less than 1 , and the performance requirements of the enterprises have not yet been completed, and they are indicators of high importance and low performance. Therefore, these are weak indicators that enterprises should focus on strengthening.

\subsection{Summary}

In general, according to the analysis results of the IPA analysis model of the financial indicators of the XX power supply bureau, we can see that the main direction of the XX power supply bureau's current key breakthroughs is cost, income, and assets. In terms of cost performance, the most important areas for enterprises to optimize are to optimize customer service costs, controllable costs, and production and operation costs, reduce unnecessary losses, and improve management. In terms of revenue performance, companies should rationally optimize power price, increase quantity of electricity sale and quantity of electricity sale within the province, and thus increase corporate income. As far as assets are concerned, the company's current assets, fixed assets and intangible assets 
are all goals that the company needs to improve at present. Enterprises should consider increasing monetary funds and improving their current assets. While fixed assets belong to the weak areas of enterprises, enterprises should increase their efforts to strengthen the fixed assets of enterprises from the aspects of power grid investment, marketing technology reform, production technology reform, main grid projects and distribution grid projects. As for the debt structure, enterprises mainly need to maintain the debt structure of enterprises and arrange the distribution of corporate debts reasonably.

\section{Case Revelation}

Based on the case analysis of the IPA model of the financial indicators of the XX power supply bureau, the paper provides the following suggestions to promote the realization of the "first-class" goal of the financial management of the enterprise in view of the objective problems in the cost, income, assets and liabilities of the enterprise.

Improve the refined management system of cost and expense. In the case of cost control, power supply cost management is regarded as a key improvement project, focusing on the control of production and operation costs. Production and operation management is especially important for enterprises. As the basis of corporate activities, good and orderly production operation management is conducive to reducing the cost of products and improving product quality, thereby improving the efficiency of business operations. Enterprises must not only control the costs incurred by a single device during its normal life cycle, but also focus on the labor costs, energy loss costs, materials, and machine schedules associated with the system as a whole. Strive to break through the weak links in power supply cost management.

Optimize corporate control business revenue. The most direct source of revenue for grid companies is electricity sales. According to the analysis of the IPA matrix, for XX power supply bureau, the revenue from regulatory business is a weak link in corporate income. To increase the business income of enterprises, it is necessary to focus on promoting the regulatory business of the development enterprise.

Strengthen the efficiency of enterprise assets management. Judging from the IPA matrix of asset-related indicators of the XX power supply bureau, the main work of the company to strengthen asset management is to manage fixed assets. To improve the efficiency of enterprise asset management, the key is to improve the awareness of asset life cycle management and improve the technical means of asset management.

Arrange the liability structure reasonably. In terms of cost, income, assets and liabilities, the performance of the enterprise in terms of liabilities has been maintained well. Compared with the other three indicators, the importance of debt to the construction goal of "first-class" enterprises is second, so the company mainly needs to maintain the current debt structure of the company and arrange the liability structure according to the characteristics of each debt. Focus on comparison of deadlines, time and costs.

The IPA basic model of the grid enterprise business financial indicators constructed in this paper is applicable to the relevant general power supply enterprises, and has certain scientific, systematic and practical characteristics. It provides useful reference for other grid companies to build "first-class" indicators.

\section{References}

Chen, X. (2013). The Amendment of Analytical Method and Its Application in Tourist Satisfaction Research. Tourism Tribune, 28(11), 59-66.

Li, Q. D. (2005). Financial Performance Evaluation and Cluster Analysis of Listed Companies. Journal of Industrial Technological Economics, (08), 146-148.

Liu, M. J. (2017). Financial Performance Evaluation of Coal Listed Enterprises Based on Factor Analysis. Finance \& Economy, (20), 158-160.

Martilla, J. A., \& James, J. C. (1977). Importance-performance analysis. Journal of Marketing, 41(1), 77-79. https://doi.org/10.2307/1250495

Peng, X. R. (2006). Research on the Theme Hotel Product Based on Customer Experience. Zhejiang University.

Tian, L., Li, B. W., \& Zhou, X. K. (2009). Tourism Destination Competitiveness: Importance-Performance Analysis. Human Geography, 24(6), 79-81+54.

Xu, H. B. (2017). Financial Performance Evaluation of State-owned Listed Companies-Based on TOPSIS-Gray Correlation Analysis. China Journal of Commerce, (27), 98-100.

Xu, N., \& Xie, R. F. (2014). Financial Performance Evaluation of Logistics Listed Companies Based on BP Neural Network. Communication of Finance and Accounting, (29), 33-35. 
Zeng, D. J., \& Bao, Z. F. (2018). Diagnosis and Improvement of Higher Vocational Courses Based on IPA Model. Vocational Technology, 17(09), 75-80.

\section{Copyrights}

Copyright for this article is retained by the author, with first publication rights granted to the journal.

This is an open-access article distributed under the terms and conditions of the Creative Commons Attribution license (http://creativecommons.org/licenses/by/4.0/). 